\title{
THE TOILING SINGLE MOTHER: DOES HER EDUCATION ATTAINMENT LEVEL MATTER IN A LEARNER'S ACADEMIC PERFORMANCE? EVIDENCE FROM SOME SOUTH AFRICAN HIGH SCHOOLS
}

\author{
Ruth O. Adesokan, \& Alfred H. Makura \\ Department of Education, Central University of Technology, P.B. X20539 Bloemfontein, Free State \\ (South Africa)
}

\begin{abstract}
This paper is part of a larger project that investigated perceived effects of single mother parenting on learners' academic performance in selected high schools in Free State, South Africa. The study is informed by Weiner's attribution theory. The research question that was formulated read: How does a single mother's level of education affect the academic performance of the learners? The quantitative method and the descriptive survey design were employed in this study. A questionnaire was used to obtain data from the respondents. A sample of 160 respondents (learners between grades 9 and 12 from single mother and both parent homes) was selected using simple random sampling technique. The data obtained was analysed using the Statistical Package for the Social Sciences (SPSS). The findings indicate that the level of education of a single mother has no significant effect on the perceived academic performance of the learner child, since $\mathrm{p}=0.985$ which is higher than the standard level of significance (0.05). Finally, the level of education of a both parents' family also has no significant effect on the perceived academic perceived of the learner child, since $\mathrm{p}=0.133$ which is higher than the standard level of significance (0.05). Based on the findings of this study, it is, recommended that, government should intensify and/or introduce education management skill sessions and the provision of free counselling services in supporting single mothers to instil some confidence in their support efforts. Establishing an education management agency to train and motivate young single mothers to ensure that their children realise their potential.
\end{abstract}

Keywords: Single mothers, parenting, academic performance, learners, South-Africa.

\section{Introduction}

Education is a fundamental component for developing, improving and stimulating human lives (Samuel, 2015). Hence, mother's education is a keystone for facilitating better academic performance in learners (Malik, 2015; Amuda and Ali, 2016). Maternal education was found to have the most consistent direct influence on children's cognitive and behavioural outcomes through a cognitively stimulating home environment (Faize and Dahar, 2011). Researchers affirm this by stating that mothers level of education is a motivational factor for mothers' support and involvement in learners' academic performance (Nyarko, 2011; Maphoso and Dikeledi, 2014; Fingerman, 2017). The legacy of apartheid in South Africa has caused lasting separation between employment and family to many black South Africans because the fathers need to migrate from their families to find work, thus living behind school going children under the sole care of their mothers (Richter and Morell, 2006; Madhavan, Townsend and Garey, 2008). It was estimated that, out of 18.6 million children in South Africa in 2013, 7.3 million stayed with their female parents while $3.3 \%$ resided with their male parents as a result of migration (Statistics South Africa, 2014; Meintjes, Hall and Sambu, 2015). Further observations state that 4.1 million of the female-parent raised children never stayed with either parent on different premises (Meintjes, et al. 2015). In addition, 71\% of children who do not finish school come from fatherless homes (single mother homes) (Statistics South Africa 2011; Fathers for life, 2013). These grim statistics begged for further interrogation focusing on the link between hitherto under-researched constructs: single mother parenting and their children's academic performance in South Africa. 


\section{Literature review}

Education plays a crucial role in the building of individuals' characters and is a basic tool used for the transmission of societal values (Rana, Nadeem and Sama, 2015; Samuel, 2015). Researchers affirm that mother's level of education influences adolescents' educational outcomes (Thompson, Alexendar and Entwisle, 1988; Asikhia, 2010). Rana, et al. (2015) point out that there is a positive relationship between parents' educational level and their children's academic performance. Nyandwi (2014) and Makura (2016) also established that learners whose parents are well educated get higher positions than those whose parents are not educated because educated parents help their children in schoolwork activities and provide best home environments that enhance academic success for their children. Similarly, mothers with higher socio-economic statuses provide more financial assistance to their children (Fingerman, Kim, Davis, Furstenberg, Birditt and Zarit, 2015). They also give their time to support and give advice and emotional support to their children when needed (Fingerman, 2017). In yet another study, Isidore, Mary, Ernest, and Victor (2014) examined the moderating effect of self-motivation on the relationship between parents' socioeconomic background on their children's academic performance at Nigerian Universities. A sample of 150 final year students from the 2012/2013 academic session registered in Business Faculties in the North, East and West regions of Nigeria were given questionnaires to provide the sought data. The authors found out that students' self-motivation (hard work) and a rich parental socio-economic background contributed to achieving academic success. In a similar vein, Ogbugo-Ololube (2016) investigated the impact of parental background on the academic performance of secondary school students in the Obio/Akpor Local Government Area of Rivers State, Nigeria. A sample size of 1,426 senior secondary school two and three (SSS 2 and 3) students was randomly selected from a population of 4,752 respondents and a structured questionnaire used to obtain data from the respondents. The findings revealed that a significant relationship existed between parents' socioeconomic and educational background, the level of income, students' family size and the students' academic performance scores.

In contrast, Ogunshola and Adewale (2012) studied the effect of parental socioeconomic status on the academic performance of students at selected high schools in the Edu Local Government Area of Kwara State, Nigeria. The study, based on a randomly selected sample of 180 students from three secondary schools, responded to a questionnaire. The study considered four factors: parental socio-economic background, parental educational background, parental educational qualification and students' health statuses. From a statistical perspective, data revealed that parental socioeconomic statuses and parental educational background have no significant effect on the academic performance of students. Similarly, Amuda and Ali (2016) examined parents' level of education as predictors of academic performance of 1200 NCE 2 and 3 students in the North-eastern states of Nigeria using a survey design. The findings revealed that, parents' level of education did not significantly predict students' academic performance.

It is generally assumed that learners' academic performance may not depend on the quality of schools and teachers. Some studies demonstrated that the extent of parental involvement based on their level of education has a vital role to play in the academic performance of their kids (Nyarko, 2011; Hafis, Tehsin, Malik, Saleem and Ali, 2013; Maphoso and Dikeledi, 2014). Maphoso and Dikeledi (2014) investigated the relationship between parental involvement and academic performance and the differences in academic performance between boarding and non-boarding (Day) school grade 12 students from the Capricorn District in the Limpopo Province of South Africa. The study sample was derived from 51 schools from six areas within the district, where 10 schools had boarding facilities, while a questionnaire was used for collecting data. The findings revealed that parents' involvement in their children's academic activities is influenced by their interest, socio-economic status and level of education. The authors opined that most parents who sent their children to boarding schools have a high level of education and a good financial background to afford the fees of such schools.

\section{Research question}

How does a single mother's level of education affect the academic performance of the learners?

\subsection{Objective}

To establish the effect of the level of a single mothers' education on the learners' academic performance. 


\subsection{Methods}

This study adopted quantitative approach and guided by positivism paradigm. Descriptive survey design was employed. Questionnaire was used to obtain data from the respondents. A sample of 160 respondents, 80 learners from single mother homes, and 80 learners from both parent homes (grade 9 to 12) were selected for the study using simple random sampling technique. The data obtained was analysed using Scientific Package for Social Sciences (SPSS).

\section{Results and discussion}

\subsection{Relationship between the level of education of a single mother and the perceived academic performance of learner child}

The relationship between the level of education of single mothers and the perceived academic performance of their children was examined using a variance analysis. The hypothesis guiding the variance analysis is presented below with the results thereof shown in table below.

\section{Hypothesis:}

H_0: The level of education of a single mother has no significant effect on perceived academic performance of the learner child.

Table 1. ANOVA Perceived Academic Performance Levels of the Learners.

\begin{tabular}{|lccccc|}
\hline & Sum of Squares & df & Mean Square & F & Sig. \\
\hline Between Groups & .019 & 2 & .010 & .015 & .985 \\
\hline Within Groups & 69.662 & 110 & .633 & & \\
\hline Total & 69.681 & 112 & & & \\
\hline
\end{tabular}

The Table draws on a one-way ANOVA test performed at 5\% level of significance to assess whether the level of education of a single mother has a significant effect on the perceived academic performance of the learner child. The perceived academic performance of the learner child was put into three levels - low, medium and high. An analysis of the presentation of variance analysis results in the above table shows that the level of education of a single mother has no significant effect on the perceived academic performance of the learner child, since $p=0.985$ is greater than $0.05[F(2,110)=0.015, p=0.985]$. Thus, the null hypothesis $\left(\mathrm{H}_{-} 0\right)$ is accepted at $5 \%$ level of significance in favour of the alternative hypothesis $\left(\mathrm{H} \_1\right)$.

\subsection{Relationship between the level of education of a both parents' family and perceived academic performance of learner child}

The variance analysis, was carried out to evaluate the relationship between the level of education of a both parents' family and the perceived academic performance of their child. The hypothesis, guiding this analysis, is presented below, while the results from the analysis are shown in the table below.

H_0: The level of education of a both parents' family has no significant effect on perceived academic performance of the learner child.

Table 2. ANOVA Test on the Level of Education of Both Parents and Perceived Academic Performance of the Learner Child.

\begin{tabular}{|lccccc|}
\hline & Sum of Squares & df & Mean Square & F & Sig. \\
\hline Between Groups & 2.241 & 2 & 1.120 & 2.097 & .133 \\
\hline Within Groups & 28.313 & 53 & .534 & & \\
\hline Total & 30.55 & 55 & & & \\
\hline
\end{tabular}

A one-way ANOVA test performed at 5\% level of significance to determine whether the level of education of a both parents' family has a significant effect on the perceived academic performance of the learner child, was carried. The perceived academic performance of the learner child was put into three levels - low, medium and high. The results from the analysis are presented in the above table and they indicate that the level of education of a both parents family has no significant effect on the perceived academic performance of the learner child, since $\mathrm{p}=0.133$ is greater than $0.05[\mathrm{~F}(2,53)=2.097, \mathrm{p}=0.133]$. Thus, the null hypothesis (H_0) is accepted at 5\% level of significance in favour of the alternative hypothesis. 


\section{Discussion}

The findings revealed herein show that there is no significant relationship between a single mother's level of education and its effect on the learners' academic performance. The Chi-square was used in to check the indicators with regards to the relationship between the mother's level of education and the child's academic performance. The results of the Chi-square test confirmed that the level of education of the parent had no significant effect on the perceived academic performance of the learner child, since $p=0.292$ and higher than the standard level of significance (0.05). The findings also indicate that the level of education of a single mother has no significant effect on the perceived academic performance of the learner child, since $\mathrm{p}=0.985$ which is higher than the standard level of significance (0.05). Finally, the level of education of a both parents' family also has no significant effect on the perceived academic perceived of the learner child, since $\mathrm{p}=0.133$ which is higher than the standard level of significance (0.05). The above findings contrast with the findings from previous studies (Rana, et al. 2015; Ogbugo-Ololube, 2016). According to Rana, et al (2015) high level educated parents have, to a certain extent, more influence on their children's positive achievements and performances in their studies at secondary school level. Ogbugo-Ololube (2016) reveals that a significant relationship exists between parents' socioeconomic and educational background, the level of income, students' family size and students' academic achievement scores.

However, this study corroborates the findings of Ogunshola and Adewale (2012) and Amuda and Ali (2016). Ogunshola and Adewale (2012) report that parental socioeconomic status and parental educational background have no significant effect on students' academic performance. In addition, Amuda and Ali (2016) conclude that fathers and mothers' level of education are not significant predictors of academic performance of students registered at Colleges of Education in the North-Eastern States of Nigeria.

\section{Conclusion}

Based on the findings, we concluded that, the level of education of a single mother has no significant effect on the academic performance of the learner.

\section{References}

Amuda B. \& Ali D. (2016). Parents' Level of Education as Predictors of Academic Performance of NCE Students of Colleges of Education in the North- Eastern States of Nigeria. Journal of Humanities and Social Science, 21 (2), 41-47.

Asikhia, O.A. (2010). Students and Teachers' Perception of the Causes of Poor Academic Performance in Ogun State Secondary Schools, Nigeria: Implication for Counselling for National Development. European Journal of Social Sciences, 13 (2), 229 -249.

Faize, F.A. \& Dabar, M.A. (2011). Effect of mother's level of Education on Secondary Grade Science Students in Pakistan. Research Journal of International Studies, 19, 13-19.

Fathers for Life (2013). Children of divorce and separation-statistics: consequences of father absence, Census. Retrieved 21 August 2017, from http://fathersforlife.org/ divorce/chlddiv.htm.

Fingerman, K.L. (2017). Millennials and Their Parents: Implications of the New Young Adulthood for Midlife Adults. Innovation in Aging, 1(3), 1-16.

Fingerman, K.L., Kim, K., Davis, E.M., Furstenberg, F.F., Jr, Birditt, K.S. \& Zarit, S.H. (2015). "I'll give you the world": Parental socioeconomic background and assistance to young adult children. Journal of Marriage and Family, 77, 844-865.

Hafis, M.W.R., Teshin, F., Malik, M.S., Saleem, M. \& Ali, M.K. (2013). Parental Involvement and Academic Achievement; A Study on Secondary School Students of Lahore, Pakistan. International Journal of Humanities and Social Science. 3(8), 1-15.

Isidore, E., Mary, O.A., Ernest, I.A. \& Victor, A. (2014). The moderating effect of self-motivation on the relationship between parents' socio-economic background and children's academic performance at Nigerian Universities. Asian Social Sciences 10(21), 1-7.

Madhavan, S., Townsend, N., \& Garey, A.I. (2008). "Absent breadwinners": Father Child connections and paternal support in rural South Africa. Journal of Southern African Studies, 34, 647-663.

Makura, A.H. (2016). Instructional Leadership Efficacy of Secondary School Principals in the Free State Province of South Africa (Paper presented at Education and Development Conference on "The effect of Innovative Technologies for Engaging Classrooms (ITEC) Project on the Science Teaching" held at the Dušana Vukasovića 73, Belgrade, Serbia on 5-7 March.) Bangkok, Thailand. 
Malik, S. (2015). Population, Poverty and Gender: A Nexus of Interconnected Issues in Achieving Universal Primary Education in Pakistan. Pakistan Journal of Social Sciences. 35, 1097-1108.

Maphoso L.S. \& Dikeledi, M. (2014). The Influence of Parental Involvement on Academic Achievement in Boarding and Non-Boarding Schools. Mediterranean Journal of Social Sciences 5(2), 155-165.

Meintjes, H., Hall, K. \& Sambu, W. (2015). Demography of South Africa's children. In: De Lannoy, A., Swartz, S., Lake, L. \& Smith, C. (Eds), South African Child Gauge. (2015). Cape Town: Children's Institute, University of Cape Town.

Nyandwi, M. (2014). Determinants of Poor Academic Performance of Secondary School Students in Sumbawanga District, Tanzania. Ma. Sokoine University of Agriculture. Morogoro, Tanzania.

Nyarko, K. (2011). The Influence of Authoritative Parenting Style on Adolescents'. Academic Achievement, 6 (2), 282-287.

Ogbugo-Ololube, R. (2016). Impact of students' parental background on academic achievement in secondary schools in Obio/Akpor Local Government area, Rivers State, Nigeria. International Journal of Scientific Research in education 9(2), 115-126.

Ogunshola, F. \& Adewale, A. M. (2012). The Effects of Parental Socio-Economic Status on Academic Performance of Students in Selected Schools in Edu LGA of Kwara State Nigeria. International Journal of Academic Research in Business and Social Sciences, 2(7), 230-239.

Rana, M.A.K., Nadeem, I., \& Sama, T. (2015). The influence of Parents Educational level on Secondary School Students Academic achievements in District Rajanpur. Journal of Education and Practice, 6(16), 1-5.

Richter, L. \& Morrell, R. (2006). Baba: Men and fatherhood in South Africa. Cape Town: Human Sciences Research Council.

RSA (Republic of South Africa). (2011) (General Household Survey Statistics). Pretoria: Government Printer.

RSA (Republic of South Africa). (2014) (General Household Survey Statistics) Pretoria: Government Printer.

Samuel, T.E. (2015). The influence of parental background on students' academic performance in physics in WASSCE 2000 - 2005. European Journal of Science and Mathematics Education, 3(1), 33- 44.

Thompson, M., Alexander, K. \& Entwisle, D. (1988). Household composition, parental expectations and school achievement. Social Forces, 67, 424-451. 